\title{
Open practices and identity: Evidence from researchers and educators' social media participation
}

\section{George Veletsianos}

George Veletsianos is Canada Research Chair in Innovative Learning and Technology and associate professor with the School of Education and Technology at Royal Roads University in Victoria B.C. His research examines learners' and scholars' practices and experiences in emerging online settings such as online social networks and open courses. Address for correspondence: Dr George Veletsianos, School of Education and Technology, Royal Roads University, 2005 Sooke Road, Victoria, BCV9B 5Y2, Canada.Email: veletsianos@gmail.com

\begin{abstract}
The ways that emerging technologies and social media are used and experienced by researchers and educators are poorly understood and inadequately researched. The goal of this study is to examine the online practices of individual scholars in order to explore and understand the activities and practices that they enact when they use social media for scholarship. Using ethnographic data collection methods and basic interpretive analysis techniques, I describe two emergent phenomena evident in scholars' social media participation: scholarly practices enacted openly in digital spaces and the self that is disentangled from academic matters. These phenomena raise issues related to "sharing," scholar identity, participation and social media as a place of gathering.
\end{abstract}

\section{Practitioner Notes}

What is already known about this topic

- Scholars use social media in teaching and research.

- Social media shapes and is shaped by scholarly practice.

- Social media can be used not just to amplify practice but also to transform scholarly endeavours.

What this paper adds

- Scholarly practices are enacted openly in digital spaces and social media.

- Academics use social media to present a self that is disentangled from academic matters.

- Scholars' digital participation practices may at times stand in stark contrast to and defy the evaluation metrics traditionally used to judge their work.

- Social media may be considered to be a place of gathering.

Implications for practice and/or policy

- Consider teaching "sharing" as a scholarly and educational practice in masters/ doctoral programs.

- Consider examining the values of networked, digital and open scholars in order to develop ways to innovate higher education.

- Consider openness and sharing as part of the academic reward structure. 
Contemporary universities are facing numerous powerful forces that may shape their future. These include changing demographics, globalization and competition, a worldwide economic downturn, curtailment of public funding, pressures for accountability, and emerging technologies (Morrison, 2003; Schwier, 2012; Siemens \& Matheos, 2010; Spanier, 2010). Emerging technologies like social media have facilitated global collaboration and sharing, but only recently have educators and researchers embraced the social and participatory nature of these in their scholarship (Veletsianos, 2012). Social media and technology have penetrated the higher education sector, and it has been posited that they have influenced scholarly functions (Pearce, Weller, Scanlon \& Kinsley, 2010) as well as the ways scholarship ${ }^{1}$ is organized, delivered, enacted and experienced (Weller, 2011). While it is debatable whether social media have led to cultural changes within academia, or if individual scholars have always had a desire for connectivity and social media simply became available to satisfy that need (Veletsianos \& Kimmons, 2012a), what is undeniable is that social media have become part of the fabric of contemporary societies and our educational systems.

At present, the ways that social media is used and experienced by scholars are poorly understood and inadequately researched (Veletsianos, 2010, 2012). The goal of this study is to examine online practices of individual scholars to answer the following research question: What activities and practices are evident when educators and researchers use social media for scholarship? By researching the online practices of networked scholars, we can gain a better understanding of scholars' values, the degrees to which their activities align with values that characterize academic institutions and the culture surrounding online academic practice. While there is a growing body of literature reporting on student experiences with social media (eg, Greenhow, 2011; Minocha, 2009; Selwyn, 2011), empirical accounts of scholars' practices in these environments are sparse, making this research worthwhile from both a practical and scholarly perspective.

To examine this topic, I first review literature relevant to scholars' digital practices. Next, I present the methods used to examine the posed research question. Finally, I present the results of this investigation and discuss my findings.

\section{Review of relevant literature}

The contemporary Web can be described as a social platform that centers on users' abilities to read, create, re-mix and contribute content in a user-friendly manner without the need for technical know-how. As a result, even though social media use patterns vary between countries, millions of individuals worldwide are participating on social media on a daily basis (Singh, Lehnert \& Bostick, 2012). Higher education scholars also use social technologies in their personal and professional lives (Moran, Seaman \& Tinti-Kane, 2012), including social networking sites (eg, Facebook), media-sharing sites (eg, YouTube) and microblogging platforms (eg, Twitter).

Jenkins, Purushotma, Weigel, Clinton and Robinson (2009) argue that we live in a participatory culture, in a society in which the consumer no longer passively receives information, media and artifacts but also produces such content. These developments are seen as promising for higher education, partly because a Web that is connected, democratic and user centered appears to align well with a socio-constructive ethos of learning, participation and knowledge creation (Lave \& Wenger, 1991; Vygotsky, 1962, 1978). As a result, recent years have seen increasing calls for the use and integration of emerging technologies in higher education settings, fuelled by a rhetoric of "radical and transformational" impact on education (McLoughlin \& Lee, 2008, para. 22). However, technological panaceas to educational problems are not new (Mishra, Koehler \& Kereluik, 2009), and Selwyn (2011) suggests that the ways that social media is used in Higher Education, and the outcomes associated with these ways, do not match the rhetoric and aspirations described in the literature. 
Emerging technologies, and social media in particular, are an integral part of digital scholarship, which is often seen as a major breakthrough in innovating the ways knowledge is created, negotiated and shared. A report funded by the Canadian Social Sciences and Humanities Research Council for example, argued that "sustaining digital scholarship in Canada will safeguard the knowledge context that ensures the continued creativity of the digital economy, contribute exemplary content to Canada's digital identity, promote the public good, boost employment and increase the numbers of flexible, highly qualified personnel" (Bretz, Brown \& McGregor, 2010 , p. 28). Emerging technologies have been defined as "tools, concepts, innovations, and advancements" that

- may not necessarily be new technologies;

- are evolving and coming into being;

- go through hype cycles;

- are neither fully understood and neither fully researched or researched in a mature way; and

- even though they offer powerful potential for change, their potential is largely unattained (Veletsianos, 2010, p. 12).

This definition suggests that emerging technologies may both shape and be shaped by practice. In other words, in the context of this paper, when emerging technologies are integrated in scholarly practice (eg, a scholar uses Twitter to network with colleagues), the technology is expected to shape the way the scholar networks with his or her colleagues, and the practice of scholarly networking will shape how the scholar will use various technologies for scholarly purposes.

While the term "digital scholarship" is often used in reference to the use of technology to conduct research more efficiently (eg, use bibliographic management tools) and provide access to it faster (eg, through e-journals), recent research suggests that social media can be used not just to amplify practice but also to transform scholarly endeavours (Weller, 2011). In an attempt to explain scholarly practices online, Veletsianos and Kimmons (2012b, p. 167) suggest that open scholarship refers to "a collection of emergent scholarly practices that espouse openness and sharing ... [encompassing] (1) Open Access and Open Publishing, (2) Open Education, including Open Educational Resources and Open Teaching, and (3) Networked Participation." This study focuses upon the phenomenon of scholars' networked participation defined as "scholars' use of participatory technologies and online social networks to share, reflect upon, critique, improve, validate, and further their scholarship” (Veletsianos \& Kimmons, 2012a, p. 768).

When employing social media in their practice, scholars appear to attempt to engage more effectively, and in different ways, with individuals and community groups interested in their scholarship (Kirkup, 2010; Kjellberg, 2010). For example, a number of researchers sought to examine the role and function of social technologies in scholarly lives. Nardi, Schiano and Gumbrecht (2004) argued that scholarly blogs could "(1) update others on activities and whereabouts, (2) express opinions to influence others, (3) seek others' opinions and feedback, (4) 'think by writing,' and (5) release emotional tension” (p. 4), while Walker (2006) noted that blogs could enable academics to launch critical discussions of their practice. In interviewing academics about their blogging practice, Kirkup (2010) found that blogs are closely connected to professional identity as they enable academics to become "public intellectuals." This evidence is corroborated by Kjellberg (2010) and Martindale and Wiley (2005) who suggest that one of the motivations for blogging is to reach multiple and diverse audiences. A number of these findings have been replicated across social technologies. For instance, Veletsianos (2012, p. 336) analyzed 4500 tweets from 45 higher education scholars and found that when using the service they "(1) shared information, resources, and media relating to their professional practice; (2) shared information about their classroom and their students; (3) requested assistance from and offered suggestions to others; (4) engaged in social commentary; (5) engaged in digital identity and impression man- 
agement; (6) sought to network and make connections with others; and (7) highlighted their participation in online networks other than Twitter."

On the other hand, scholars' social media practices are rife with tensions. Evidence from Procter et al (2010), for example, seems to suggest that social media supplements rather than displaces traditional media because current forms of information exchange are "adequate" and "entrenched" in academic reward and promotion structures. For example, emerging forms of scholarly engagement involving social media may reach different and diverse audiences, but the field lacks evaluation metrics and guidelines about how academics can report the impact of their scholarship resulting from such engagement. And even though new forms of peer evaluation may be devised (eg, reader evaluations), and some of these have already been used by journals (eg, PLOS One, 2013), alternative forms of scholarly evaluation are not yet well understood by academia (Johnson, Levine, Smith \& Stone, 2010).

In addition, in a small-scale study of 14 researchers at the University of Milan, Esposito (2013) found that even though a number of early adopters exist, some are doubtful and uncertain about both the tools and the values underlying digital and open scholarship. Further, in an in-depth study of three researchers' lived experiences with online social networks, Veletsianos and Kimmons (2013) suggest that scholars' use of social media may be characterized by a personalprofessional tension: When using social media, scholars in the aforementioned study negotiate their participation in ways that allow them to maintain appropriate and meaningful connections with professional and non-professional contacts. Thus, they (1) structure their participation such that others can scrutinize it or (2) limit their visible participation so as to reduce exposure to the tension between the personal and professional spheres of life. Such managed participation appears to be important, as prevalent social media activities (eg, "friending" acquaintances, colleagues, and family) appear to introduce conundrums for scholars. At the same time, Hall (2011) suggests that learning technology is not neutral and, rather than assuming its democratic, emancipatory or transformative potential, researchers need to critically examine the narratives of educational technology within the broader corporate and political agenda that it exists. Towards this goal, Veletsianos and Kimmons (2012b) identify a number of assumptions and challenges of the movement towards open and digital scholarship (eg, social stratification and exclusion), noting that even though aspirations to broaden access to knowledge "might arise from the inadequacies and shortcomings of the status quo," this does not make digital/open scholarship systems, decisions and initiatives "exemplar or just." For instance, it is often assumed that open systems may foster an environment of equality and democratization (eg, everyone can have free access to articles published under an open access license), but in reality, some scholars may be able to benefit more than others as a result of their "knowledge, wealth, power, and ability" (c.f. Chander \& Sunder, 2004).

While researchers have begun examining the experiences and practices of academics and scholars who participate on social media, investigations that observe and examine situated practices directly are limited. In particular, ethnographic methods may yield findings that are not captured in studies guided by the research approaches utilized so far in examining the topic of this paper. In addition, ethnographic investigations of situated practices may contribute to an understanding of the social, political and cultural factors that influence technology use and nonuse. Such investigations appear to be desperately needed in the educational technology field (Selwyn, 2010). This investigation's contributions therefore may be valuable in painting a more accurate and holistic picture of scholarly practices in online spaces.

\section{Research question}

In this study, I posed the following research question: what activities and practices arise when researchers and educators use social media? 


\section{Methods}

The overarching objective of this research is to make sense of practices with social media and to understand why scholars use emerging technologies, such as social media, in the ways that they do. These phenomena are complex and the research question posed above, as well as the method of analysis to answer that question, seek to uncover ways individuals participate in online settings.

This study was influenced by cyberethnography (Ward, 1999) and virtual ethnography (Hine, 2000). However, unlike these analytical approaches, and akin to Watulak (2011), instead of doing ethnography (Green \& Bloome, 1997), my use of ethnography is limited to ethnographic data collection methods. Specifically, I have been an active participant and contributor on social media sites. In these spaces, I interact with educators, researchers and students within the field of educational technology, participate in virtual events (eg, open courses) and keep a journal of digital artifacts, reflections and observations. This journal consists of observations, thoughts, reflections, screenshots and news articles. Some of these artifacts are derived from a wide array of social media sites such as blogs, microblogging sites and video-sharing sites. This journal centers around three questions, "What am I observing in my social media participation with regard to scholarly practice? What phenomena and/or issues arise? What do these observations mean for scholarly practice, and how can we make sense of them?” This journal, guided by my observations and experiences, then becomes the main data source that I analyze to answer the research question posed above. The result of that analysis is the qualitative study reported herein.

Data analysis was guided by the constant comparative method (Glaser \& Strauss, 1967) in which I coded data to note emerging patterns. In particular, I took a piece of data (eg, a journal entry), coded it, compared it with other pieces of data (eg, a category, a journal entry, a screenshot), examined whether the data were similar or different, and developed additional categories to capture similarities and differences between the data. This process was iterative. In other words, I coded data, entered new data (ie, continued journaling) and continued comparing new and existing data and categories in an ongoing fashion.

At times, new data changed my understanding of the practices I was observing. At other times, new data reinforced my understanding of what I was observing. The patterns that I identified in my data were compiled and reanalyzed across journal entries. Journaling and analysis are ongoing processes, but after going through the process multiple times, I felt that the data had been saturated and could be grouped into the two major themes that I discuss below.

It is important to note that this study attempts to understand practices and phenomena in a reflexive, autobiographical and reflective lens. It is reflexive and autobiographical because I use my personal experiences as a way to frame the phenomena under examination, and reflective because I reflect upon both my experiences and the participation of others within social media. Even though the insights I gleaned from these artifacts were triangulated with personal experiences and theoretical constructs, the research method that I followed poses threats to validity and reliability. By being so close to the culture under investigation, it is possible that I have internalized the values and norms that characterize scholars who use social media. In addition, my life experiences as a learner, researcher, educator and user of social technologies influence the ways with which I view the world. However, rather than ignoring these threats, while conducting this investigation, I have consciously sought to contain and keep my prior experiences in check-a process known as "bracketing" (Giorgi, 1997). I have done this by continuously reflecting on my analysis and interpretation, and persistently questioning the degree to which this analysis reflects my own preunderstandings of the phenomena under investigation. In addition, in presenting the results, I have attempted to provide rich descriptions of the phenomena examined so as to enable readers to evaluate the plausibility of the results (Merriam, 1995). 
Methodologically, this investigation lies within the constructivist realm, as I do not purport to uncover a monolithic truth explaining the ways scholars act and participate online. Rather, I believe that there exist multiple truths, some that are complementary and some that are contradictory. Furthermore, these truths may coexist. For example, it may be true that some scholars are comfortable being on social media, which others may feel trepidation about participating online. It might also be true that the source of that uneasiness varies. For instance, some scholars might feel uneasy about participation because they see no real benefit to participation, while others see benefits but the potential costs of participation (eg, privacy concerns) outweigh those benefits.

Finally, the anecdotes and stories that I share below may not appear new or surprising to individuals who participate on social media. However, they are novel in the sense that they help describe and make explicit actions enacted on social media spaces that may either be implicit or left unexamined. As such, this essay may help us better understand how some scholars use social media in today's environment and what their values are.

\section{Results}

I remember the exact moment when I decided to join Twitter and created a professional blog. I was reading chapter proposals for a book that I was editing and one proposal made such a big impression upon me that I decided to spend more time using these technologies outside of the courses that I was teaching. At first, I often struggled with the notion of public participation on social media, of "putting myself out there," publishing draft ideas and sharing details of my professional and nonprofessional life that I assumed others would find incomplete, dull or irrelevant. In retrospect, the source of this struggle was partly the training and scholarly enculturation that I received during my graduate degree. This training, implicit as it may have been, highlighted the notion that researchers: (1) can be "scooped out of ideas" if they share ideas prematurely and (2) are experts, knowledgeable in their field of study, confident of their work and should present themselves as such.

Since then, I have also learned that I am not the only scholar facing this struggle. Others have expressed this struggle eloquently noting that publishing "half-baked" ideas might be a dangerous career move for scholars because, even though an individual might benefit from thinking through ideas via writing, others may judge one's work in a decontextualized manner without necessarily observing or understanding how a particular blog entry, for example, evolved over time. The struggles and tensions scholars may experience when participating on social media have also been reported elsewhere (eg, Veletsianos \& Kimmons, 2013) wherein participants (1) wondered whether the time spent on social media could have been spent more productively elsewhere, and (2) struggled with the degree to which they should share professional versus nonprofessional information. These issues point to an increasing tension between personal and professional identity, the spectrum of sharing that lies between the two, and the perception of who a scholar is and what she/he does.

Sharing and issues of scholar identity (eg, the degree to which scholarly identity is distinct from nonprofessional identity) permeate social media participation. These issues are not limited to social media. In discussing the tattoos of faculty members for example, Leonard (2012, para. 6) notes that "[i]n a university culture, where faculty are often reduced to numbers-grant dollars, student credit hours, teaching-evaluation scores, publication numbers-tattoos offer a space to disentangle our individual selves from the bureaucratic and corporate university." In the same way, the social media uses that I have seen in my ethnographic journey appear to center around issues of identity and control. To explore these issues, I describe two emergent phenomena: scholarly practices enacted openly in digital spaces and the self that is disentangled from academic matters. 
Scholarly practices enacted openly in digital spaces

The image of the "lone scholar" tirelessly working on his or her research in a dimly lit office is in stark contrast to the connected and visible scholarly practices enacted online by the scholars that I have encountered in this investigation. While a number of specialized tools have been developed specifically for networked scholarly practice (eg, academia.edu, Mendeley), scholars have also used their own individual websites, most often blogs, as spaces in which they enact and pursue their scholarship in a visible manner. In addition, personal websites often serve as areas where faculty's digital presence is aggregated and various scholarly artifacts are featured. For example, personal websites frequently feature the creator's blog, Twitter feed, reading list, teaching artifacts (eg, syllabi), scholarly artifacts (eg, copies of publications) and links to topics of interest (eg, professional organizations) or blogs that the individual reads.

The question that is of interest here is: what types of scholarly practices are made visible through scholars' online participation? Examples of activities that I have frequently observed being enacted in public digital spaces include:

- announcements. Examples include announcements of publications, awards and job opportunities;

- sharing drafts of manuscripts and requesting/receiving feedback on them;

- developing and releasing textbooks written as part of a course (eg, Amado et al, 2011; Correia, 2012);

- sharing syllabi and instructional activities;

- live streaming or sharing video/photographs from one's own teaching;

- live blogging and live tweeting a conference keynote or session;

- authoring and participating in the writing of collaborative documents pertaining to conference sessions/workshop;

- engaging in debates and commentary on professional issues;

- teaching. For example, scholars have taught courses that were made freely available to anyone who wished to participate (eg, Hilton, Graham, Rich, \& Wiley, 2010);

- making one's tenure and promotion materials publicly available;

- reflecting on and conversing about the doctoral process and thesis/dissertation. Doctoral students have used blogs and wikis to share their work, and reflect upon and document their progress. Self-organized systems through which some of these activities are enacted have also been formed. For example, \#PhDChat is an active online community initiated by doctoral students. Individuals in the community use social media to update each other on their progress, share resources, learn about the profession, socialize and support each other;

- creating video trailers to describe, promote and highlight academic artifacts such as books;

- help-seeking with professional activities (eg, research, teaching), enacted in the form of crowdsourcing. For example, individuals have asked for help in locating research literature.

To further understand the values of scholars who use social media for scholarship, we can examine two of these practices in more detail. The first practice is the use of video trailers to describe, promote and highlight academic artifacts. These videos are often produced by individual faculty members, posted on a video-sharing website such as YouTube and are then cross-posted on blogs and shared across social media services such as Twitter and Facebook. These videos are often of short duration (ie, about 1-2 minutes long) and attempt to relay the central tenets of the book, course, project or publication they advertise in a meaningful and appealing way. The fact that video trailers were originally conceptualized, developed and shared by individual faculty members (vis-à-vis by a production team at the academic institution which employs the individual) is important because it highlights (1) the ease with which individual scholars can develop and share media pertaining to their scholarship, (2) the creative opportunities afforded to schol- 
ars by emerging technologies, and (3) scholars' willingness to share their work outside of formal and institutional structures. In reflecting upon this practice, we may note that faculty members, who are not traditionally trained in media production, are seeking ways to engage with audiences who may be outside the reach of the dissemination methods that have historically been at their disposal. While the concept of media creation, curation, re-mixing and recirculation is not new (c.f. Jenkins et al, 2009), one may see here the emergence of an academic subculture firmly grounded on participatory ideals.

The second practice that requires deeper analysis is that of accessing research literature through crowdsourcing. Imagine being at a university whose library does not have access to a journal that has published an article that you need for your teaching or research. Or, that even though you have access to the journal, the year in which the paper was published falls outside of your institution's subscription dates. For example, the journal imposes a 6-month lag between the time the paper is published and the time it becomes available electronically. What options are available to you? You could purchase the article. Or, you could email the article's author and ask for a copy of the paper. Alternatively, you could search for the article online in the hopes that the author has self-archived the paper (eg, on his/her personal website). In addition to these approaches, I have discovered that individuals have also appropriated social technologies to find and share journal papers. Reminiscent of peer-to-peer networks for music sharing, scholars have used PirateUniversity.org, ThePaperBay.com, the Scholar subreddit ${ }^{2}$ and the \#ICanHazPdf hashtag ${ }^{3}$ to access scholarship that they need. On these websites, individuals request papers that they do not have access to, and those who have access (eg, through their institution's libraries) provide them with a copy of the papers. Coverdale (2012) has also discussed the role of file-sharing sites in retrieving and providing access to academic work. These activities are important because they suggest that individuals are willing and able to circumvent and defy restrictions to the sharing of knowledge and research. Kroll (2011) describes this as "an act civil disobedience toward the scientific publishing enterprise." In fact, open access to scholarship is a value that is close to the hearts and minds of numerous scholars who use the Internet for professional purposes, and even though they may not publicly embrace or endorse the activities described above, they often make their stance in support of open access known. For example, a number of them have used their blogs to explain that they refuse to publish in or review for journals that are not embracing open access ideals.

\section{The self that is disentangled from academic matters}

Even though social technologies have been repurposed for scholarly activities, they were not originally designed for those purposes (Hemmi, Bayne \& Land, 2009). As the design of online social networks is framed around social and informal sharing, the presentation of the self that is disentangled from academic matters is a theme that is persistent in my observations of scholars' activities online. Scholars use social media for nonprofessional purposes, revealing multiple dimensions of their selves. For example, scholars have shared not just their scholarly successes, but their vulnerabilities and struggles (eg, with a divorce) and sought help with personal issues and causes that they are passionate about (eg, equal rights legislation and raising awareness concerning debilitating diseases). Importantly, it appears that engagement with and sharing about issues unrelated to the profession is a value that is celebrated by this community. It is not uncommon, for example, to encounter blog entries discussing the positive outcomes of social sharing and Twitter profiles proudly declaring that updates are composed of a mix of personal and professional tweets. As I have argued elsewhere (Veletsianos, 2012), even though some status updates, such as meal preferences, may appear to serve limited professional purposes when seen out of context, they might actually serve significant social functions.

Scholars' participation in the "childhood walk" Internet meme exemplifies this theme. An Internet meme is a concept or artifact created by individuals (eg, an image with a caption, a 


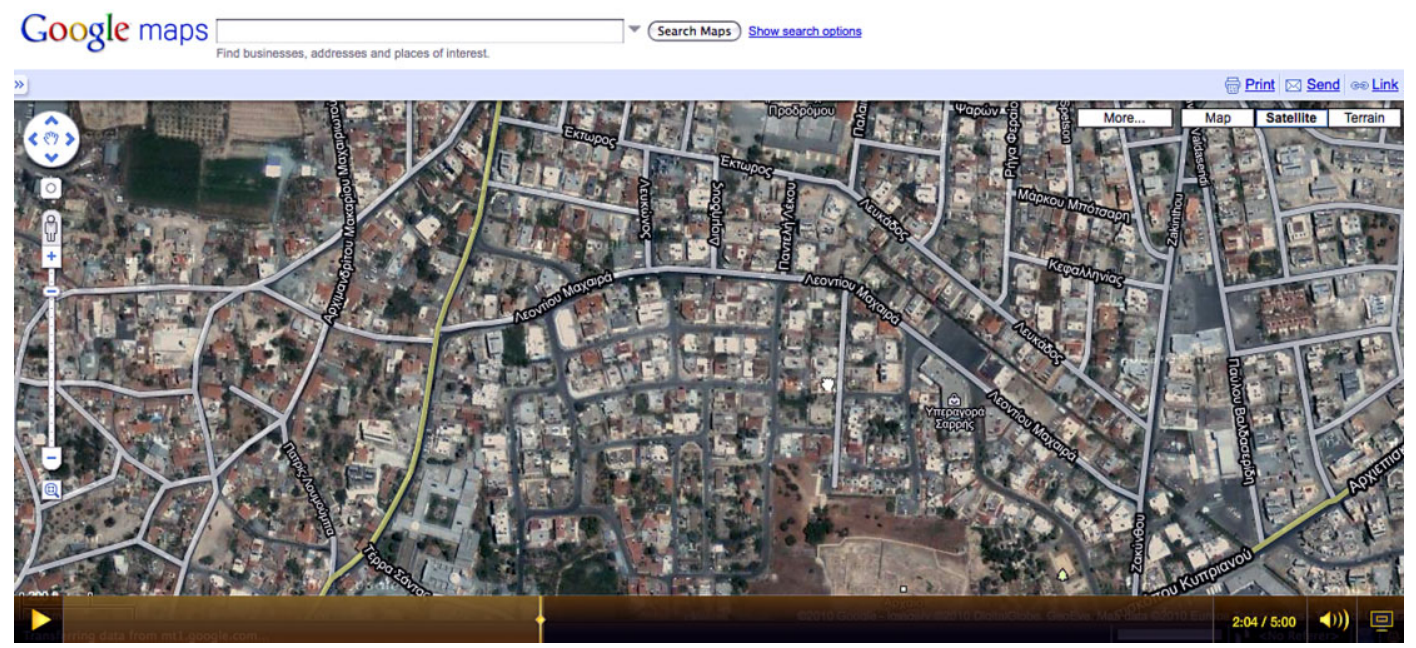

Figure 1: The author's version of "a childhood walk"

re-enactment of an activity such as a dance) that spreads virally on the Internet. Examples of popular memes include: LOLcats, Three Wolf Moon T-shirt, Numa Numa dance and, more recently, the Harlem Shake videos. "A childhood walk" was a concept developed by Internet performance artist Ze Frank, in which he asked individuals to use Google Street View to share stories and screenshots of childhood walks and memories. Numerous individuals contributed stories (archived at http://www.zefrank.com/the_walk/), and among those, a number of researchers and educators shared their stories of childhood walks (eg, Figure 1). These stories present a self that is often unseen outside of small-group gatherings, and may enable individuals to develop relationships and bonds.

\section{Discussion}

In this paper, I explored practices and activities that arise when researchers and educators use social media. I focused upon two phenomena and described how individuals have enacted scholarly practices openly in digital spaces and revealed a self that is disentangled from academic matters. While these practices may not be new, or even uniform across scholars and educators participating in social media, they nonetheless highlight a number of issues that are worthy of consideration and reflection.

"Sharing" is a persistent concept in these findings. The individuals who are embracing sharing practices are finding value in doing so, and often speak out in favor of sharing. It is not unusual for example to encounter quotes such as "good things happen to those who share," or "sharing is caring" or "education is sharing." These quotes illustrate and exemplify the values of this subculture. While faculty members have historically shared their work with each other (eg, through letters, telephone calls and conference presentations), and open access publishing is gaining increasing acceptance (Scanlon, in press; Weller, 2011), educators and researchers are increasingly sharing their scholarship online in informal, open spaces. Wiley and Green (2012, p. 82) even argue that "[e]ducation is, first and foremost, an enterprise of sharing. In fact, sharing is the sole means by which education is effected." However, education, both K-12 to higher education, has generally lacked a culture of sharing. Barab, Makinster, Moore and Cunningham (2001) note that "change efforts [in K-12] have often been unsuccessful due in large part to the lack of a culture of sharing among teachers (Chism, 1985)." If we were to consider the values of this subculture moving forward and follow the example they set, what role would "sharing" play 
in our practice? A core value of this subculture is that sharing should be treated as a scholarly and educational practice. Toward this goal, the practice of sharing needs to be taught in teacher preparation and doctoral programs alike, in the same way that student-centered pedagogies, digital citizenship and new media literacies are taught. The increasing calls for open access scholarship are a step towards this direction.

Scholars' social media practices and innovations (eg, sharing draft versions of a manuscript, accessing literature through crowdsourcing) appear to question traditional elements of scholarly practice. Such elements (eg, peer-review, publishing refined rather than in-progress work) are elements upon which scholarship has been established and is being enacted today. However, techno-cultural advances appear to have led to increasing calls to reevaluate the ways scholarship is disseminated, negotiated and evaluated. Taken further, some of the digital scholarly practices I observed could be characterized as small acts of defiance against institutional norms, tenure and promotion practices, and the status quo. For example, tenure and promotion materials are not usually made publicly available. On the other hand, this research has also demonstrated that the alternative is also true. Namely, that social media have been used in supporting commonly accepted forms of scholarly engagement such as knowledge creation and dissemination. As modern universities are facing pressures to change within a world increasingly dominated by managerial and corporate practices that value quantitative metrics of evaluation, scholars' digital participation may at times stand in stark contrast to and defy the evaluation metrics traditionally used to judge their work. Viewing scholarly participation online with this lens allows us to ask a set of future research questions: what challenges, if any, are scholars facing at their institutions as they enact the practices described in this paper? How have scholars' institutions responded to these practices, and how do these responses differ across institutions?

The practices described in this paper suggest that social media can be viewed as a place where scholars can congregate to share their work, ideas and experiences. This place is similar to a conference gathering or a meeting of colleagues at a writing retreat. Through social media gatherings, distributed individuals build ties, bonds and solidarity, even when they may have not met each other face-to-face. Shared values (eg, openness) contribute to the formation of bonds and solidarity. A worthwhile question to ask in future research might be, how has this community developed over time? And what role has the technology played in its development?

While prior research has explored the degree to which seniority may influence participation in digital scholarship (eg, Kirkup, 2010), and researchers have argued that "professional seniority [gave professors] the confidence to invest time in non-traditional academic production” (p. 21), this research has not differentiated participation between individuals at different levels of their career. Instead, this research has focused on identifying emergent phenomena that were common across participants. However, it is important to note that individuals face different challenges and may come across different opportunities at different levels of their academic career. Therefore, it would be worthwhile for future research to explore how scholars use social media to cope with the expectations of their academic roles (eg, being a doctoral student vs. being a newly hired faculty member).

Finally, this paper shows that academics have taken advantage of the social and playful nature of participatory technologies to share aspects of their life that are often considered private. Academic identity online is an issue that requires deeper analysis as recent investigations have sought to explore the relationship between identity and online participation. Stewart (2012), for example, sees six key selves in social media, or six ways of being. These are: the performatice, public self; the quantified or articulated self; the asynchronous self; the polysocial or augmented reality self; and the neo-liberal or branded self. These descriptors overlap with the types of participation described in this paper. In addition, Kimmons and Veletsianos (2013) have found that 
when participating in online social networks, individuals put forth fragments of their identity that they deem to be acceptable to others. In short, individuals in their research presented their "true self" online, but actively managed that presentation to conform to what they perceived others would deem socially acceptable. It may be worthwhile for future work to further explore how scholars perceive and construct their identity online.

\section{Conclusion}

In this paper, I have examined practices and activities that arise when researchers and educators use social media. The practices identified are varied. A lot of these practices are not new. Rather, they are enacted in different spaces and under different constraints. Yet, they are novel. They enable us to examine the values of a subculture of digital scholars and allow us to seek further understanding of why scholars engage in the activities that they do on social media.

\section{Acknowledgements}

The STELLAR Fellowship Mobility Program supported this research. The views and results presented in this report should not be taken to represent the views or opinions of the STELLAR Fellowship Mobility Program.

\section{Notes}

1. In this paper, "scholarship" refers to research, teaching and service activities.

2. At the time of writing, Reddit was a popular content aggregator whose content was contributed by users. A subreddit was a community of users who shared a common interest (eg, exercise, veganism, education, etc).

3. A hashtag refers to the Twitter practice of adding the \# symbol in front of a word in order to categorize a message for indexing/retrieval. For example, a popular hashtag is \#edtech and is used by individuals to categorize a message as being relevant to educational technology.

\section{References}

Amado, M., Ashton, K., Ashton, S., Bostwick, J., Clements, G., Darnall, R. et al (2011). Project management for instructional designers. Retrieved February 10, from http://pm4id.org/

Barab, S., Makinster, J., Moore, J. \& Cunningham, D. (2001). Designing and building an on-line community: the struggle to support sociability in the inquiry learning forum. Educational Technology Research and Development, 49, 4, 71-96.

Bretz, A., Brown, S. \& McGregor, H. (2010). Lasting change: sustaining digital scholarship and culture in Canada. Report of the Sustaining Digital Scholarship for Sustainable Culture Group. Retrieved July 14, 2011, from http://tinyurl.com/sustaindigsc

Chander, A. \& Sunder, M. (2004). The romance of the public domain. California Law Review, 92, 5, $1331-$ 1373.

Chism, N. (1985). The place of peer interaction in teacher development: findings from a case study. Paper presented at the 1985 Annual Meeting of the American Educational Research Association (AERA), Chicago, IL.

Correia, A.-P. (Ed.) (2012). Breaking the mold: an educational perspective on diffusion of innovation. Retrieved February 10, from http://en.wikibooks.org/wiki/Breaking_the_Mold:_An_Educational_Perspective_on_ Diffusion_of_Innovation

Coverdale, A. (2012). Free academic books here! Retrieved November 20, 2012, from http://phdblog.net/freeacademic-books-here/

Esposito, A. (2013). Neither digital or open. Just researchers. Views on digital/open scholarship practices in an Italian university. First Monday, 18. Retrieved May 1, 2013, from http://firstmonday.org/htbin/ cgiwrap/bin/ojs/index.php/fm/article/view/3881/3404

Giorgi, A. (1997). The theory, practice, and evaluation of the phenomenological method as a qualitative research procedure. Journal of Phenomenological Psychology, 28, 2, 235-260.

Glaser, B. \& Strauss, A. (1967). The discovery of grounded theory: strategies for qualitative research. Chicago, IL: Aldine.

Green, J. \& Bloome, D. (1997). Ethnography and ethnographers of and in education: a situated perspective. In J. Flood, S. Heath \& D. Lapp (Eds), A Handbook of research on teaching literacy through the communicative and visual arts (pp. 181-202). New York: Simon \& Schuster Macmillan. 
Greenhow, C. (2011). Online social networks and learning. On the Horizon, 19, 1, 4-12.

Hall, R. (2011). Revealing the transformatory moment of learning technology: the place of critical social theory. Research in Learning Technology, 19, 3, 273-284.

Hemmi, A., Bayne, S. \& Land, R. (2009). The appropriation and repurposing of social technologies in higher education. Journal of Computer Assisted Learning, 25, 1, 19-30.

Hilton, J. L., Graham, C., Rich, P. \& Wiley, D. (2010). Using online technologies to extend a classroom to learners at a distance. Distance Education, 31, 1, 77-92.

Hine, C. (2000). Virtual ethnography. London: Sage Publications.

Jenkins, H., Purushotma, R., Weigel, M., Clinton, K. \& Robinson, A. J. (2009). Confronting the challenges of participatory culture: media education for the 21st century. Cambridge, MA: The MIT Press.

Johnson, L., Levine, A., Smith, R. \& Stone, S. (2010). The 2010 horizon report. The New Media Consortium. Retrieved February 15, 2013, from http://www.nmc.org/pdf/2010-Horizon-Report.pdf

Kimmons, R., \& Veletsianos, G. (2013). The fragmented educator: Social networking sites, acceptable identity fragments, and the identity constellation. Under review.

Kirkup, G. (2010). Academic blogging: academic practice and academic identity. London Review of Education, $8,1,75-84$.

Kjellberg, S. (2010). I am a blogging researcher: motivations for blogging in a scholarly context. First Monday, 15, 8, 1-17.

Kroll, D. (2011). \#icanhazpdf: Civil disobedience? Retrieved on November 21, 2012, from http://cenblog. org/terra-sigillata/2011/12/22/icanhazpdf-civil-disobedience/

Lave, J. \& Wenger, E. (1991). Situated learning: legitimate peripheral participation. Cambridge, UK: Cambridge University Press.

Leonard, D. (2012). The inked academic body. The Chronicle of Higher Education. Retrieved October 26, 2012, from http://chronicle.com/blogs/conversation/2012/10/25/the-inked-academic-body/

Martindale, T. \& Wiley, D. A. (2005). Using weblogs in scholarship and teaching. TechTrends, 49, 2, 55-61.

McLoughlin, C. \& Lee, M. (2008). Future leaning landscapes: transforming pedagogy through social software. Innovate, 4, 5. Retrieved May 31, 2008, from http://tinyurl.com/6qs376q

Merriam, S. (1995). What can you tell from an $\mathrm{N}$ of 1?: issues of validity and reliability in qualitative research. PAACE Journal of Lifelong Learning, 4, 51-60.

Minocha, S. (2009). An empirically-grounded study on the effective use of social software in education. Education and Training, 51, 5/6, 381-394.

Mishra, P., Koehler, M. J. \& Kereluik, K. (2009). The song remains the same: looking back to the future of educational technology. TechTrends, 53, 5, 48-53.

Moran, M., Seaman, J. \& Tinti-Kane, H. (2012). Blogs, wikis, podcasts, and Facebook: how today's higher education faculty use social media. Boston, MA: Pearson Learning Solutions.

Morrison, J. (2003). U.S. higher education in transition. On the Horizon, 11, 1, 6-10.

Nardi, B. A., Schiano, D. J. \& Gumbrecht, M. (2004). Blogging as social activity, or, would you let 900 million people read your diary? Proceedings of the "O4 ACM Conference on CSCW (pp. 222-231).

Pearce, N., Weller, M., Scanlon, E. \& Kinsley, S. (2010). Digital scholarship considered: how new technologies could transform academic work. in education, 16, 1. Retrieved May 1, 2013, from http://ineducation. ca/article/digital-scholarship-considered-how-new-technologies-could-transform-academic-work

PLoS ONE (2013). Article-level metrics information. Retrieved January 11, 2013, from http://www.plosone. org/static/almInfo

Procter, R., Williams, R., Stewart, J., Poschen, M., Snee, H., Voss, A. et al (2010). Adoption and use of Web 2.0 in scholarly communications. Philosophical Transactions of the Royal Society, 368, 4039-4056.

Scanlon, E. (in press). Scholarship in the digital age: open educational resources, publication, and public engagement. British Journal of Educational Technology.

Schwier, R. (2012). The corrosive influence of competition, growth, and accountability on institutions of higher education. Journal of Computing in Higher Education, 24, 2, 96-103.

Selwyn, N. (2010). Looking beyond learning: notes towards the critical study of educational technology. Journal of Computer Assisted Learning, 26, 1, 65-73.

Selwyn, N. (2011). Social media in higher education. In A. Gladman (Ed.), The Europa world of learning (pp. 1-9). London, UK: Routledge.

Siemens, G. \& Matheos, K. (2010). Systemic changes in higher education. in Education, 16, 1. Retrieved July 19, 2012, from http://ineducation.ca/article/systemic-changes-higher-education

Singh, N., Lehnert, K. \& Bostick, K. (2012). Global social media usage: insights into reaching consumers worldwide. Thunderbird International Business Review, 54, 5, 683-700.

Spanier, G. (2010). Creating adaptable universities. Innovative Higher Education, 35, 2, 91-99. 
Stewart, B. (2012). Digital identities: six key selves in networked publics. Retrieved May 10, 2012, from http://theory.cribchronicles.com/2012/05/06/digital-identities-six-key-selves/

Veletsianos, G. (2010). A definition of emerging technologies for education. In G. Veletsianos (Ed.), Emerging technologies in distance education (pp. 3-22). Edmonton, AB: Athabasca University Press.

Veletsianos, G. (2012). Higher education scholars' participation and practices on twitter. Journal of Computer Assisted Learning, 28, 4, 336-349.

Veletsianos, G. \& Kimmons, R. (2012a). Networked participatory scholarship: emergent techno-cultural pressures toward open and digital scholarship in online networks. Computers \& Education, 58, 2, 766774.

Veletsianos, G. \& Kimmons, R. (2012b). Assumptions and challenges of open scholarship. The International Review of Research in Open and Distance Learning, 13, 4, 166-189.

Veletsianos, G. \& Kimmons, R. (2013). Scholars and faculty members lived experiences in online social networks. The Internet and Higher Education, 16, 1, 43-50.

Vygotsky, L. S. (1962). Thought and language. Cambridge, MA: MIT Press.

Vygotsky, L. S. (1978). Mind in society. Cambridge, MA: Harvard University Press.

Walker, J. (2006). Blogging from inside the ivory tower. In A. Bruns \& J. Jacobs (Eds), Uses of blogs (pp. 127138). New York, NY: Peter Lang.

Ward, K. J. (1999). Cyber-ethnography and the emergence of the virtually new community. Journal of Information Technology, 14, 1, 95-105.

Watulak, L. S. (2011). 'I'm not a computer person': negotiating participation in academic discourses. British Journal of Educational Technology, 43, 1, 109-118.

Weller, M. (2011). The digital scholar: how technology is transforming scholarly practice. London, UK: Bloomsbury Academic.

Wiley, D. \& Green, C. (2012). Why openness in education? In D. Oblinger (Ed.), Game changers: education and information technologies (pp. 81-89). Washington, D.C.: Educause. 